\title{
Olfactory responses of Argentine stem weevil to herbivory and endophyte-colonisation in perennial ryegrass
}

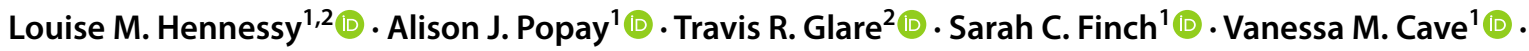 \\ Michael Rostás ${ }^{2,3}$ (1)
}

Received: 10 November 2020 / Revised: 27 March 2021 / Accepted: 3 April 2021 / Published online: 21 April 2021

(c) The Author(s) 2021

\begin{abstract}
Argentine stem weevil adults (ASW, Listronotus bonariensis) feed on the leaves of agricultural grasses and their larvae mine the pseudostem, causing extensive damage that can result in plant death. Plants emit volatiles that serve as signals to host-searching insects and these odours can be altered by both herbivory and fungal endophyte-infection. This study investigated whether ASW adults utilise olfaction to identify their host plants, perennial ryegrass (Lolium perenne), and if conspecific herbivory or the presence of Epichloë festucae var. lolii fungal endophytes (strain wild-type or AR1) influenced such responses. Results from olfactometer bioassays established that ASW adults were able to utilise their olfactory response to orient towards volatiles released by perennial ryegrass and further, the weevils displayed a preference for plants previously damaged by conspecific weevils. However, there was no evidence that weevils had the ability to distinguish between endophyte-infected and endophyte-free plants using olfaction alone. Using a push-pull extraction technique, thirteen volatile compounds were identified in the blend released by perennial ryegrass. Endophyte and herbivory were found to alter these volatile compounds and quantities emitted by this forage grass. This study suggests that despite observing differences in the plant volatile blend, ASW do not perceive endophyte (wild-type and AR1) using olfaction alone and must rely on other cues, e.g. contact chemoreception or post-ingestional malaise, to detect the presence of a bioactive endophyte in an otherwise acceptable host plant.
\end{abstract}

Keywords Listronotus bonariensis $\cdot$ Lolium perenne $\cdot$ Epichlö̈ $\cdot$ Herbivore included plant volatiles $\cdot$ Host choice $\cdot$ Volatiles

\section{Key message}

- Research investigating the mechanisms involved in perception of grasses by pests is sparse.

- This study investigated olfactory responses of Argentine stem weevil to perennial ryegrass.

Communicated by Lara Jaber.

Louise M. Hennessy

louise.hennessy@agresearch.co.nz

1 AgResearch Limited, Ruakura Research Centre, Hamilton, New Zealand

2 Bio-Protection Research Centre, Lincoln University, Lincoln, Canterbury, New Zealand

3 Agricultural Entomology, Department of Crop Sciences, University of Göttingen, Göttingen, Germany
- ASW oriented towards volatiles released by ryegrass and preferred those previously damaged by ASW.

- Endophyte altered the volatile bouquet, but there was no evidence that this affected ASW preference.

- An understanding of perception can identify opportunities to improve integrated pest management.

\section{Introduction}

The Argentine stem weevil (ASW, Listronotus bonariensis) was accidentally introduced to New Zealand early in the twentieth century from South America (Williams et al. 1994) and has since become a key economic pest of agricultural grasses (Ferguson et al. 2018; Prestidge et al. 1991). It is also known to cause damage to pasture grasses in Australia and South America (Hardy et al. 1979). Adult weevils feed on the leaves, creating distinctive 'window-like' feeding scars on the adaxial leaf surface. Eggs are deposited in the 
pseudostem and stem boring larvae mine the centre of tillers, causing extensive damage which can result in plant death. The scarcity of natural enemies in New Zealand has allowed ASW to flourish on perennial ryegrass, the predominant species in these highly productive, species-poor grasslands (Goldson et al. 2020). Biological control of ASW involves fungal endophytes and an introduced parasitic wasp, Microctonus hyperodae, which parasitizes adult weevils resulting in sterilization and eventual death (Barker et al. 1984a, 1984b; Ferguson et al. 2018; Goldson et al. 1994, 1998b; Popay et al. 1999; Thom et al. 2013).

Asexual fungal endophytes of the genus Epichloë do not have an external form (asymptomatic) and colonise agricultural grasses in a defensive mutualistic association (Clay 1988). In this interaction endophyte gains shelter, nutrients and a means of transmission (within seed). In return, the host gains protection from herbivorous pests (Hennessy et al. 2016; Jensen and Popay 2007; Popay et al. 2003b; Prestidge et al. 1982) due to endophyte-derived alkaloids which can have deterrent and/or toxic effects on insects (Patchett et al. 2011; Popay and Cox 2016; Popay et al. 1990; Rowan et al. 1990). Wild-type (WT, also known as 'common-toxic' or 'standard endophyte') strains (genotype) of Epichloë festucae var. lolii were likely introduced to New Zealand in ryegrass seed imported in the late 19th and early twentieth centuries and in the 1980s these were found to produce three alkaloids peramine, lolitrem B and ergovaline (Gallagher et al. 1984, 1981; Rowan et al. 1986; Rowan and Shaw 1987). These compounds are active against insects (Prestidge and Gallagher 1985; Rowan et al. 1990) but, lolitrem B and ergovaline are also mammalian toxins, causing ryegrass staggers and heat stress, in grazing livestock under certain conditions (Easton et al. 1996; Gallagher et al. 1984). Following this discovery, researchers sought to identify strains of endophyte that produced different chemical profiles sourced from the more diverse European grasslands (Tapper and Latch 1999). Strains that produced alkaloids which were active against insects, but not the aforementioned mammalian toxins (or produced these compounds at low concentration), have been successfully commercialised and are sold to farmers within the seed of host plants in New Zealand, Australia, the United States of America and South America (Caradus et al. 2013b; Johnson and Caradus 2019; Johnson et al. 2013; Latch and Christensen 1985). These strains are known as 'selected' (or 'novel') endophytes and two predominant commercial strains in New Zealand's intensive pastoral ecosystems are AR1 and AR37 (Caradus et al. 2013a; Johnson et al. 2013). Although pastures containing the WT strain are common in areas of New Zealand that are less accessible and are not frequently re-sown, newer pastures typically contain 'selected' endophytes. Insects have a choice of food plants as grass swards on-farm contain a mixture of endophyte-free and endophyte-infected plants growing in close proximity due to imperfect endophyte transmission and sensitivity of seed to storage conditions (Hume and Barker 2005; Hume et al. 2013; Rolston et al. 1986). AR1 and the naturalised WT strain are known to reduce ASW adult feeding on perennial and Italian ryegrass (Barker et al. 1984b; Popay et al. 1999; Popay and Thom 2009). The deterrent effects of these endophytes have primarily been attributed to the alkaloid, peramine, as demonstrated in semi-synthetic diet experiments (Popay et al. 1990; Rowan et al. 1990; Rowan and Gaynor 1986). AR37 produces epoxy-janthitrems (Finch et al. 2020, 2010) but not peramine and has no negative effect on ASW adult feeding and egg laying but it strongly reduces larval feeding (Popay and Wyatt 1995).

Locating host plants, for feeding and oviposition is vital for phytophagous insects; plant volatiles can play an important role in this process. All plants release diverse blends of volatile organic compounds which host-searching insects may detect using olfaction. Qualitative and quantitative differences in volatile emissions can occur in response to various abiotic and biotic factors including herbivory (herbivore-induced plant volatiles, HIPVs) and endophyteinfection (Delphia et al. 2007; Esteban et al. 2021; Li et al. 2014; Pańka et al. 2013; Yue et al. 2001). HIPVs are considered to be an indirect plant defence mechanism or 'cry for help' as they can attract natural enemies of the attacking herbivorous insect (Fuchs and Krauss 2019). These blends are also known to attract or deter host-searching herbivores (Bernasconi et al. 1998; Dicke and Baldwin 2010; Turlings et al. 1990; Van Tol et al. 2002). How insects respond to volatile blends altered by endophyte-infection is not well understood but two previous studies have shown that insects are able to exploit these differences. Qawasmeh et al. (2015) demonstrated in Y-tube olfactometer experiments that African black beetle adults (Heteronychus arator) could utilise olfaction to detect differences in the volatiles emitted by AR1 or WT endophyte strains, but not the AR37 endophyte strain. This finding is interesting given ryegrass infected with the AR1 endophyte is only weakly deterrent to African black beetle, whereas AR37 provides ryegrass with a strong level of protection (Popay and Baltus 2001; Popay and Thom 2009). Rostás et al. (2015) also investigated the role of volatiles and found that root feeding larvae of the native New Zealand grass grub (Costelytra giveni formerly Costelytra zealandica) were able to exploit differences in the plant volatile blend to avoid an endophyte-infected (Epichlö̈ uncinata formerly Neotyphodium uncinatum) hybrid grass (Festuca pratensis x Lolium perenne cultivar 'GrubOUT®'). This has demonstrated that Epichloë endophytes, which colonise above-ground tissues, are also capable of altering the volatile blend emitted by roots which has in turn altered the distribution and feeding habits of below-ground herbivores. 
It is important to understand what mechanisms and/or compounds are involved in altering insect behaviour towards their host plants. This immediately applies to endophyteinfected plants, as such insights may aid in the identification of novel pest management strategies. Therefore, the purpose of this study was to investigate specifically the role of plant volatiles in the orientation and host-selection behaviour of ASW adults in response to herbivory and Epichlö fungal endophytes (AR1 and WT strains). Still-air olfactometer experiments were used to examine whether ASW uses olfaction to locate host plants and then to select endophytefree in preference to endophyte-infected ryegrass. ASW olfactory responses to herbivore-damaged plants were also investigated as was the combined effects of endophyte and herbivory. Volatiles emitted by damaged and undamaged, endophyte-free and AR1-infected ryegrass were collected and analysed, to explore possible differences between the volatile profiles emitted by these different treatments.

\section{Methods}

Six olfactory experiments (Table 1) were performed using a still-air olfactometer to investigate responses of ASW adults to their host plant, to hosts previously damaged by conspecific insects and hosts infected with a bioactive endophyte strain (AR1 or WT). Olfactometer experiments were conducted between 24th Janurary and 8th March 2017 (summer to early autumn) when ASW adults were active and had not entered reproductive diapause (Goldson 1981). Volatile organic compounds emitted from undamaged, damaged and endophyte-infected perennial ryegrass were collected using a push-pull extraction technique and analysed using gaschromatography mass-spectrometry.

\section{Establishment of ryegrass plants and endophyte testing}

Perennial ryegrass plants (Lolium perenne cultivar 'Grasslands Samson') infected with E. festucae var. lolii (strain AR1 or WT) and endophyte-free plants were established from seed obtained from the Margot Forde Germplasm
Centre (AgResearch, Palmerston North, New Zealand). Seeds were germinated in Petri dishes $(90 \mathrm{~mm})$ lined with damp filter paper ( $1 \mathrm{~mL}$ tap water) and held inside a darkened container at $20{ }^{\circ} \mathrm{C}$ for 7-10 days. Germinated seedlings were planted into individual, identifiable positions in polystyrene planter boxes filled with fresh potting mix (Daltons $\left.{ }^{\mathrm{TM}}\right)$. Plants were maintained with regular hand-watering and trimming.

All plants were tested for endophyte-infection using a tissue print immunoassay at least 6-week post germination. Tillers (1-2 per plant) were cut from the base of the plant, where endophyte mycelium is concentrated, and dead sheath material and soil removed. The cut surface was pressed firmly onto nitrocellulose paper. 'Blots' were developed using an immunoassay described by Simpson et al. (2012) and those that contained endophyte were differentiated based on colour. Only plants of the correct endophyte-infection status were kept for experiments.

\section{Argentine stem weevil}

Field-collected weevils were chosen for this study as it is important to understand how naturally occurring, diverse populations respond to perennial ryegrass. Argentine stem weevil adults were collected from pastures (Ruakura Research Centre, Hamilton, New Zealand) no more than $48 \mathrm{~h}$ before the beginning of each experiment using a reverse modified blower vacuum. ASW was removed from the litter in the collection and sexed using the external morphological features as described by Goldson and Emberson (1981). The weevils were placed into a $-20{ }^{\circ} \mathrm{C}$ freezer for six minutes, to reduce their activity and allow examination of the thorax under a stereomicroscope. Female weevils were chosen for the experiments as sex-specific responses have been documented in the insect literature with females often showing stronger responses to plant volatiles than males (McGraw et al. 2011; Szendrei and Rodriguez-Saona 2010). All weevils were starved for $24 \mathrm{~h}$ at room temperature prior to inclusion in the olfactometer experiments.

Following completion of each experiment the sex of each weevil was confirmed by dissection (Goldson and Emberson 1981). Due to the difficulties in sexing ASW using external
Table 1 Treatments in the six still-air olfactometer experiments conducted to assess responses of Argentine stem weevil adults (Listronotus bonariensis) to host plants, endophyte and conspecific herbivory. Weevils were presented with a choice between two odour sources in the olfactometer

\begin{tabular}{lll}
\hline $\begin{array}{l}\text { Olfactometer experi- } \\
\text { ment }\end{array}$ & Odour source 1 & Odour source 2 \\
\hline 1 & Endophyte-free ryegrass & Damp cotton wool \\
2 & Undamaged endophyte-free ryegrass & Damaged endophyte-free ryegrass \\
3 & Endophyte-free ryegrass & AR1-infected ryegrass \\
4 & Endophyte-free ryegrass & Wild-type (WT) infected ryegrass \\
5 & Undamaged AR1-infected ryegrass & Damaged AR1-infected ryegrass \\
6 & Damaged endophyte-free ryegrass & Damaged AR1-infected ryegrass \\
\hline
\end{tabular}


features a small number of males were identified as having been included in experiments. In addition, the presence or absence of parasitoid larvae (M. hyperodae) was also noted (Goldson and Emberson 1981). Although it is possible to purge parasitoids from a population of field-collected weevils, this was not done as parasitism rates were expected to be low and rearing insects in a colony could have influenced their behaviour and host-selection in olfactometer experiments.

\section{Olfactometer}

A glass still-air olfactometer (as shown (Online Resource 1)) was modified from that of Van Tol et al. (2002) and the experimental protocol adapted to ASW's behavioural and morphological characteristics. The design allowed ASW adults to select between two odour sources or to remain in the central arena. The olfactometer consisted of a large glass Petri dish (145 mm diameter excluding thickness of glass) with two small circular openings $(13 \mathrm{~mm}$ diameter) on the bottom section of the dish $(82 \mathrm{~mm}$ apart and $16 \mathrm{~mm}$ from the rim). Attached to each opening was a short tube ( $26 \mathrm{~mm}$ long, $13 \mathrm{~mm}$ diameter) which led into larger cylindrical holding tubes $(69 \mathrm{~mm}$ long $\times 44 \mathrm{~mm}$ diameter). Below each holding tube and separated by a fine mesh barrier $(100 \mathrm{~mm} \times 100 \mathrm{~mm})$ were glass cups $(73 \mathrm{~mm}$ length $\times 44 \mathrm{~mm}$ diameter, $52 \mathrm{~mm}$ diameter at the top rim) that held whole plants. The Petri dish became the 'test arena' where $10 \mathrm{ASW}$ adults were placed at the beginning of each experiment. Weevils' choices were recorded based on the number of weevils found in different cylindrical holding tubes.

\section{Olfactory experiments}

The size of each plant was reduced 5-6 d prior to each bioassay ( $3 \mathrm{~d}$ prior in Experiment 2 date 1 ) by removing tillers so that all plants had approximately eight tillers. Plants were repotted into individual plastic specimen vials $(75 \mathrm{~mL})$ which were placed into boxes filled with damp sand and maintained in a glasshouse until required.

Each plant was removed from its container, the roots placed into a plastic bag and the whole plant folded into a glass cup. A clean square of mesh was positioned over the top of each cup and the olfactometer constructed. Dry cotton wool was placed around the edges of the Petri dish and Teflon thread seal tape (brand Plumb it) was used to cover small gaps between joints.

Olfactometers were placed into a controlled environment chamber $\left(20^{\circ} \mathrm{C}, 80 \%\right.$ humidity, no light) for $2 \mathrm{~h}$ to allow diffusion of plant volatiles. Ten weevils that had been starved for $24 \mathrm{~h}$ were added to the test arena and left to select an odour source overnight (15-16 h), a time when weevils are most active during the summer (Barker and Pottinger 1986). In the morning, olfactometers were deconstructed and the position of each weevil recorded (test arena, treatment or control). Weevils were frozen for later dissection to confirm sex and check for parasitism. Each olfactometer was rinsed with warm tap water, purified water and then wiped clean with petroleum spirit and acetone before being left to bench dry. To prevent contamination, new mesh squares were made for each experiment. Plant position in each olfactometer was randomly orientated between the two possible positions.

\section{Olfactory response to host plants}

Two olfactometer experiments were carried out to identify whether ASW utilise olfaction to find perennial ryegrass host plants and to investigate whether conspecific herbivory affects weevil response. In Experiment 1, ASW were presented with a choice between the volatile blend released by their host plant (endophyte-free ryegrass) and a control of damp cotton wool in still-air olfactometers ( 9 replicates, 89 weevils [ 87 females, 1 male, 1 damaged and not able to be dissected]). Humidity was measured (McGregors weather station/ thermometer M440) and in three of the replicates the humidity of the plant cup and control cup were compared. This showed that $500 \mathrm{mg}$ of cotton wool plus $2 \mathrm{~mL}$ of MilliQ water was sufficient to create a similar humidity in control cups. In Experiment 2, ASW were presented with a choice between undamaged and damaged endophyte-free ryegrass (18 replicate olfactometers, 180 weevils [178 females, 2 males]).

ASW that were used to damage plants for Experiment 2 were collected fresh from the field, sorted into plastic specimen containers and starved for $24 \mathrm{~h}$. Forty-eight hours before the beginning of the olfactometer experiment, all plants (including those that were to remain undamaged) were placed individually into plastic containers with lids $(170 \mathrm{~mm} \times 120 \mathrm{~mm} \times 70 \mathrm{~mm})$, one side of which consisted of fine mesh. Containers were placed into a glasshouse and plants were watered as required. For the damaged plants, five weevils were caged onto each plant. Weevils were removed from plants immediately before the bioassay was performed.

\section{Olfactory response to endophyte-infected plants}

Four olfactometer experiments were carried out to investigate the role of olfaction in the selection of endophyte-free and endophyte-infected (AR1 or WT) plants by ASW. In Experiment 3, weevils were offered a choice between AR1infected and endophyte-free ryegrass (29 replicate olfactometers, 284 weevils [265 females, 19 males]) and between WT-infected and endophyte-free ryegrass in Experiment 4 (19 replicates, 184 weevils [173 females, 8 males, 3 sex undetermined]). Experiments 5 and 6 investigated whether 
endophyte-infection influenced the herbivore-induced volatile blend and subsequent insect responses. In Experiment 5 , ASW were presented with a choice between undamaged and damaged AR1-infected ryegrass plants (19 replicates, 187 weevils [186 females, 1 male]) and in Experiment 6, weevils were presented with a choice between damaged endophyte-free and damaged AR1-infected plants (20 replicates, 197 weevils [196 females, 1 male]). This is summarised in Table 1.

In Experiments 5 and 6, plants were damaged prior to each bioassay following the methods described above for Experiment 2. In Experiment 5, seven, rather than five weevils were caged onto each AR1-infected plant to ensure sufficient feeding damage. Five weevils were caged on to each endophyte-free and AR1-infected plant in Experiment 6. Weevils were removed from plants before bioassays were carried out.

\section{Collection and analysis of volatile organic compounds}

Emissions were collected from ryegrass plants in June 2017 (New Zealand winter). A push-pull system was used for dynamic headspace sampling of the volatiles emitted by perennial ryegrass. Volatile compounds were collected from undamaged endophyte-free, damaged endophyte-free, undamaged AR1-infected and damaged AR1-infected perennial ryegrass plants. For each plant-endophyte combination, two 12-week-old plants were re-planted into a single specimen container $(150 \mathrm{~mL})$ and placed into a glass collection vessel. Volatiles were collected separately from five replicate plant pairings of the same treatment simultaneously. To account for contamination in the system, a collection was made from vessels that contained empty specimen containers only. A compressed air cylinder was used to push charcoal-filtered air into each vessel at a rate of $0.8 \mathrm{~L} / \mathrm{min}$. Air was pulled through a SuperQ absorbent filter (30 mg ARS Inc., Gainesville, FL, USA), at the same rate, using a vacuum pump (ILMVAC GmbH, Germany). Volatiles were collected for $4 \mathrm{~h}$. Compounds were eluted from the SuperQ filter with methylene chloride $(150 \mu \mathrm{L})$ and $200 \mathrm{ng}$ tetralin (Sigma-Aldrich, Australia) was then added as an internal standard to each sample. Samples were analysed by a gas chromatograph coupled with a mass spectrometer (Shimadzu GC-MS-QP2010 Ultra) which was equipped with a Restek Rtx-5 ms fused silica capillary column $(30.0 \mathrm{~m} \times 0.25 \mathrm{~mm}$ i.d. $\times 0.25 \mu \mathrm{m}$, Bellefonte, PA, USA). The ionisation voltage was $70 \mathrm{~V}$. Samples $(1.5 \mu \mathrm{L})$ were injected in pulsed splitless mode ( $241 \mathrm{kPa}$ pulse for $39 \mathrm{~s}$ ) at $220{ }^{\circ} \mathrm{C}$. Initial oven temperature was set at $35{ }^{\circ} \mathrm{C}$ held for 3 min then increased at $8{ }^{\circ} \mathrm{C} / \mathrm{min}$ to $320^{\circ} \mathrm{C}$ for $8 \mathrm{~min}$. The carrier gas was helium $(1.75 \mathrm{~mL} / \mathrm{min})$. Volatile compounds were analysed using GC-MS solution version 4.11 and were tentatively identified by comparing their mass spectra with entries in the databank NIST 11. In addition, experimental retention indices were compared to those listed on the National Institute of Standard and Technology (NIST) Webbook (https://webbook.nist. gov/chemistry/). Volatiles were quantified by comparing individual volatile peak areas to that of the internal standard.

\section{Statistical analyses}

A multinomial regression analysis was performed on weevil position data (i.e. number of weevils from a replicate in the test arena, treatment position and control position) in each olfactometer experiment. The effect of parasitism (a fixed factor with two levels) was analysed using a linear mixed model fitted by residual maximum likelihood (REML). The random model comprised the nuisance factors; replicate, orientation (two levels; left and right), date (where applicable), sex (only applied to Experiment 4) and two factors relating to the position of the olfactometer in the controlled environment chamber; shelf (two levels - bottom or top) and side (two levels but this was omitted for Experiments 2 and 5 as these were confounded with date). Replicate was the only nuisance factor included in the analysis of data from Experiment 1 , due to lower replication. All random effects were constrained to be positive. The statistical significance of the fixed effect of parasitism was assessed using approximate F-tests at the 5\% significance level. In Experiment 3, as 19 males were mistakenly included in the experiment, the fixed model included an additive effect for sex.

An analysis of variance (ANOVA) was performed on feeding scar data in Experiments 2, 5 and 6. Statistical significance was determined using Fisher's unprotected least significant difference post hoc test conducted at the 5\% significance level.

A principal component analysis (PCA) was performed on volatile emission data. The PCA analysis was based on a correlation matrix. Replicate 1 of the treatment 'AR1infected undamaged' was removed from the analysis due to some missing values. A general or unbalanced (as appropriate) one-way ANOVA was performed on emission data for each of the compounds separately. A log transformation was necessary for some of the compounds. In data sets which included zero values, half the value of the smallest concentrations was added to the data prior to analysis. For some treatments just one of the five replicates contained a value above zero and these treatments could not be included in the ANOVA. Statistical significance was determined using Fisher's unprotected least significant difference post hoc test conducted at the 5\% significance level. A false discovery rate (FDR) correction was also applied (Benjamini and Hochberg 1995) and the adjusted $P$-values are reported.

All statistical analyses were conducted in Genstat 18th or 20th edition. 


\section{Results}

\section{Olfactory experiments}

The number of weevils that moved from the test arena and selected one of the treatments was high, with response rates of $84 \%-93 \%$ in all experiments.

\section{Olfactory response to host plants}

In Experiment 1, ASW adults were significantly $(P<0.001$, $\mathrm{t}=4.97$, r.d.f. [residual degrees of freedom] $=16$, Fig. 1 ) attracted to the volatile blend released by perennial ryegrass (endophyte-free), when given a choice between their host plant and a control of damp cotton wool. On average more weevils selected herbivore damaged plants when presented with a choice between the volatile blend emitted by damaged and undamaged endophyte-free ryegrass plants in Experiment 2 , but this difference was not statistically significant $(P=0.095, \mathrm{t}=1.67$, r.d.f. $=34$, Fig. 1$)$.

\section{Olfactory response to endophyte-infected plants}

The effect of endophyte on host-selection was investigated by presenting weevils with a choice between the volatile blend emitted by endophyte-free and either AR1 (Experiment 3) or WT (Experiment 4) endophyte-infected perennial ryegrass. No significant differences in host-selection were found in response to either endophyte strain (Experiment
3, $P=0.114, \mathrm{t}=1.58$, r.d.f. $=56$, Fig. 2 and Experiment 4, $P=0.105, \mathrm{t}=1.62$, r.d.f $=36$, Fig. 2 ).

The combined effects of endophyte and herbivory were assessed by presenting weevils with a choice between damaged and undamaged AR1-infected ryegrass plants (Experiment 5). In this experiment an average of $5.2( \pm 0.52$ $( \pm$ s.e.m. $)$ ) weevils selected the damaged plants, while 3.8 $( \pm 0.45)$ weevils chose undamaged ryegrass $(P=0.057$, $\mathrm{t}=1.91$, r.d.f. $=36$, Fig. 2). Because there was no evidence of an effect of endophyte on host-selection (Experiment 3 and 4), the results from Experiments 2 and 5 were combined and analysed. In this case, significantly more weevils selected damaged plants $(P=0.011, \mathrm{t}=2.53$, r.d.f 72, Fig. 2$)$. The total number of feeding scars on each damaged plant in Experiment 2 and 5 were assessed after the experiment. On average 29 (range 1-78) feeding scars were found on AR1infected plants and 58 (range 13-102) on endophyte-free plants. Seven AR1-infected plants had fewer than 15 feeding scars compared to just one endophyte-free plant. Damaged endophyte-free plants from Experiment 2 had significantly $(P<0.001$, r.d.f $=17)$ more feeding scars than damaged AR1-infected plants from Experiment 5.

In Experiment 6, ASW were presented with a choice between damaged endophyte-free and damaged AR1infected plants. The average number of ASW that selected each plant type was similar and no significant difference in host-selection was identified $(P=0.377, \mathrm{t}=0.88$, r.d.f. $=38$, Fig. 2). When the number of feeding scars on these plants was assessed, endophyte-free plants were found to have significantly more $(P<0.001$, r.d.f 19$)$ damage with an average
Fig. 1 Response of Argentine stem weevil adults (ASW, Listronotus bonariensis) in still-air olfactometers to the volatiles released by endophyte-free perennial ryegrass (PR, Lolium perenne). In Experiment 1 (Exp. 1), ASW were presented with a choice between perennial ryegrass $(\mathrm{PR})$ or a control of damp cotton wool (control) $(n=9)$, and in Experiment 2 (Exp. 2) undamaged perennial ryegrass $(\mathrm{PR})$ and ryegrass previously damaged by conspecific herbivory $(\mathrm{PR}+\mathrm{H})(n=18)$. Bars represent the average number of weevils (out of a total of 10) found in each chamber of the still-air olfactometer ( \pm s.e.m [standard error of the mean]). Different letters above bars indicate significant differences; multinomial regression analysis, $P<0.05$
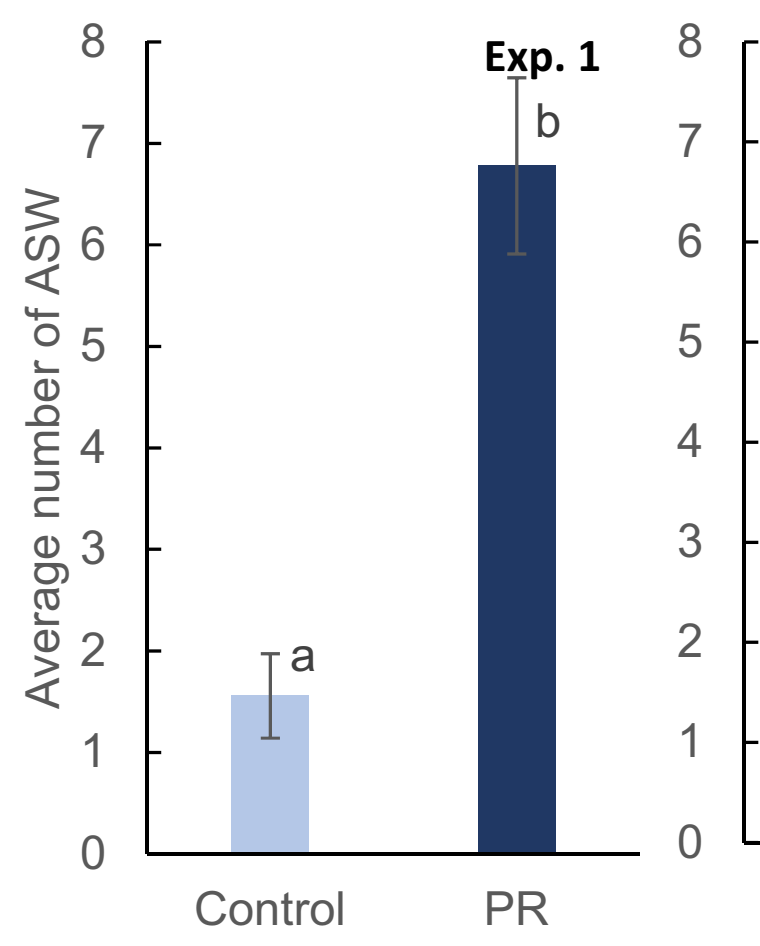

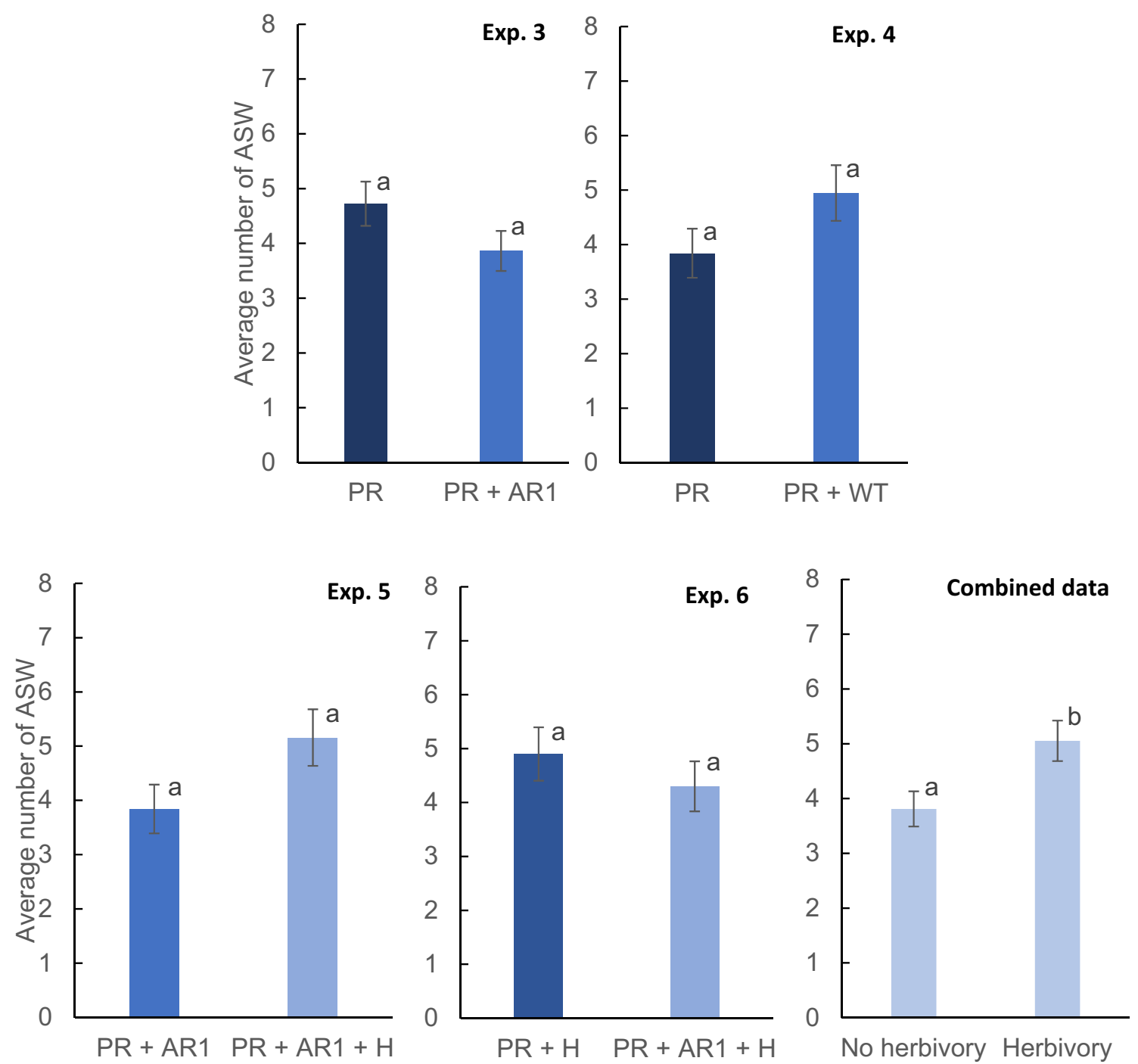

Fig. 2 Response of Argentine stem weevil adults (ASW, Listronotus bonariensis) in olfactometer experiments to the volatiles released by endophyte-free or endophyte-infected (Epichlö̈ festucae variant lolii) perennial ryegrass (Lolium perenne) both with and without damage by conspecific insects. ASW were presented with a choice between endophyte-free perennial ryegrass (PR) and perennial ryegrass infected with the AR1 endophyte (PR + AR1) $(n=29)$ in Experiment 3 (Exp. 3); endophyte-free perennial ryegrass (PR) and wild-type infected ryegrass $(\mathrm{PR}+\mathrm{WT})(n=19)$ in Experiment 4 (Exp. 4); undamaged AR1-infected ryegrass (PR + AR1) and dam-

of 103 (range 31-207) scars per plant compared to an average of 49 (range 5-87) on AR1-infected plants.

\section{Parasitism rate and sex of Argentine stem we}

Parasitism rates and sex were confirmed at the conclusion of each experiment by dissection. Four weevils were unable to be successfully dissected and were not included in the data analysis. On rare occasions (10 weevils) only sex and not parasitism was able to be determined due to degradation aged AR1-infected ryegrass $(\mathrm{PR}+\mathrm{AR} 1+\mathrm{H})(n=19)$ in Experiment 5 (Exp. 5); damaged endophyte-free ryegrass $(\mathrm{PR}+\mathrm{H})$ and damaged AR1-infected ryegrass (PR $+\mathrm{AR} 1+\mathrm{H})$ (Experiment $6, n=20)$ in Experiment 6 (Exp. 6). The final graph represents the Combined data of damaged AR1 and endophyte-free plants and undamaged AR1 and endophyte-free plants in Experiments 2 (data included in previous figure) and 5. Bars represent the average number of weevils found in each chamber of the still-air olfactometer $( \pm$ s.e.m). Different letters above bars indicate significant differences; multinomial regression analysis, $P<0.05$

of the sample. Parasitism was between 12 and $23 \%$ in all experiments except for Experiment 3, in which $32 \%$ of weevils were parasitized. There was evidence of a significant effect of parasitism in Experiment 4, when $61 \%$ of non-parasitized weevils $(n=78)$ were found to select the WT-infected ryegrass plants compared to $35 \%$ of the parasitized weevils $(n=11)\left(P=0.007, \mathrm{~F}_{1158}=7.37\right.$, s.e.d. [standard error of the difference $]=0.096$ ). There was no evidence of a significant effect of parasitism in the remaining experiments. Dissection results confirmed that no more than two males were found 
in Experiments $1(1.1 \%), 2$ (1.1\%), $5(0.5 \%)$ and $6(0.5 \%)$ but eight males (4.4\%) were found in Experiment 4 and 19 (6.7\%) in Experiment 3. In Experiment 3, 46\% of females selected AR1-infected plants $(n=109)$ compared to $23 \%$ of males $(n=3)\left(P=0.064, \mathrm{~F}_{1244}=3.45\right.$, s.e.d. $\left.=0.1262\right)$. Interestingly, more males selected endophyte-free $(n=13)$ over AR1-infected $(n=3)$ host plants ( 3 weevils did not select a plant).

\section{Volatile organic compounds}

Herbage volatiles were collected from both damaged and undamaged ryegrass plants that were endophyte-free or infected with strain AR1 using dynamic headspace sampling and analysed using GC-MS. There was an average of 126 (range 106-157) feeding scars on endophyte-free plants compared to an average of 52 (range 45-57) scars on AR1infected plants. Quantitative and qualitative differences were found between treatments. Thirteen compounds were found and nine were tentatively identified.

A principal component analysis (PCA) was performed on emission data of the 11 compounds that could be quantified. Principal components 1 and 2 explained $59.36 \%$ of the variation (Fig. 3). In the PCA, replicates of the same treatment tended to cluster together, and this was particularly evident in the AR1-infected undamaged treatment. The compounds that were highly positively correlated $(r=0.80)$ with each other were trans- $\beta$-ocimene and cis- $\beta$-ocimene, indole and trans- $\beta$-ocimene, as well as indole and cis- $\beta$-ocimene.

\section{Endophyte}

Endophyte presence in undamaged plants significantly $(P<0.05)$ affected the average emission rate of an unknown compound found at RT 16.69 , with endophyte-free plants emitting a higher amount of the compound than AR1infected plants (Fig. 4). Endophyte also significantly $(P<0.05)$ reduced the emission of 3,4-dimethylcyclohexanol. An unknown compound found at RT 16.15 was only found in one replicate of undamaged endophyte-free plants and emission was lower than that found in AR1 undamaged plants. The average emission rate of several other compounds varied between undamaged endophyte-free and undamaged AR1-infected plants, but these differences were not significant (note that the median values are presented in Table 2, while mean values are presented in Fig. 4 (mean values are not given in Table 2 due to transformation of data for some compounds)). An unknown compound, which occurred at RT 16.87 , could not be accurately quantified as it eluted closely with a contaminant, but interestingly this compound was only detected in AR1-infected plants and not endophyte-free plants. This unknown volatile has a molecular ion of 204, suggesting that this compound, and the unknown compound found at RT 16.15 , could be sesquiterpenes.
Fig. 3 Scatterplot of principal component score 1 and 2 for volatile emission data from replicate perennial ryegrass (Lolium perenne) plants, either endophyte-free (PR) or infected with the endophyte AR1 (PR + AR1) and each with ( $\mathrm{H}=$ herbivory) or without feeding damage caused by Argentine stem weevil adults (Listronotus bonariensis). Replicate 1 of AR1-infected undamaged plants was removed due to missing values

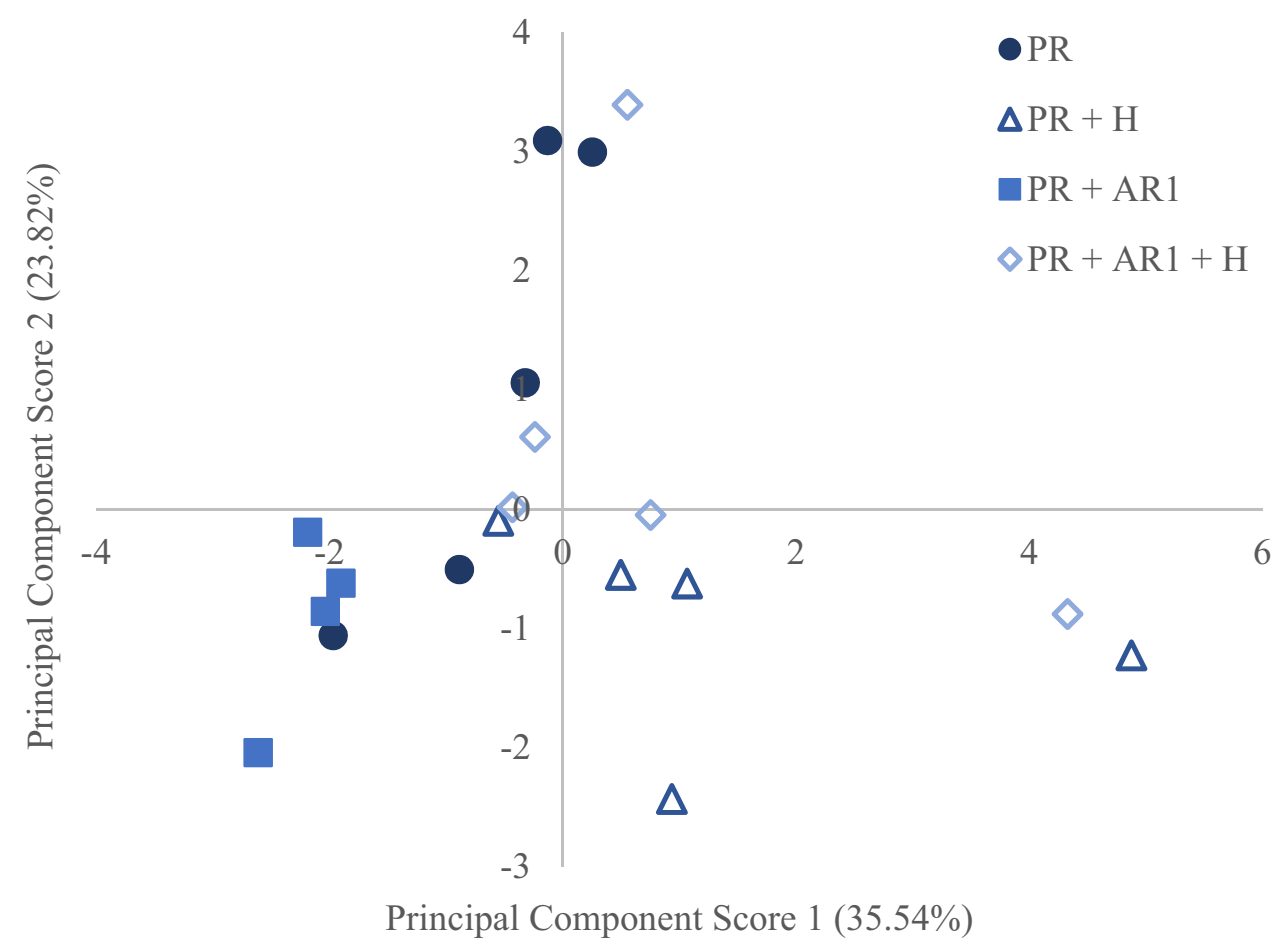


Fig. 4 Average emission (ng/g fresh weight/h) rates of the seven compounds that differed significantly between the four treatments; undamaged perennial ryegrass (PR), herbivore damaged perennial ryegrass $(\mathrm{PR}+\mathrm{H})$, undamaged ryegrass infected with the AR1 endophyte (PR + AR1) and herbivore damaged ryegrass infected with the AR1 endophyte $(\mathrm{PR}+\mathrm{AR} 1+\mathrm{H})$. Where required averages and $95 \%$ confidence intervals (C.I.) are back-transformed from the log scale. Compounds presented are; cis- $\beta$-ocimene $( \pm 95 \%$ C.I., ANOVA of log transformed data), trans- $\beta$-ocimene $( \pm 95 \%$ C.I., ANOVA of log transformed data), 3,4-dimethylcyclohexanol ( $\pm 95 \%$ C.I., ANOVA of log transformed data), unknown compound found at retention time 16.69 ( \pm s.e.m, unbalanced ANOVA of untransformed data), Dihydroactinolide $( \pm 95 \%$ C.I., ANOVA of log transformed data), neophytadiene ( \pm s.e.m., ANOVA of untransformed data), and 2-pentadecanone, 6, 10, 14-trimethyl ( \pm s.e.m, unbalanced ANOVA of untransformed data). Different letters above bars denote significant differences; analysis of variance, Fisher's unprotected least significant difference posthoc test conducted at the 5\% significance level
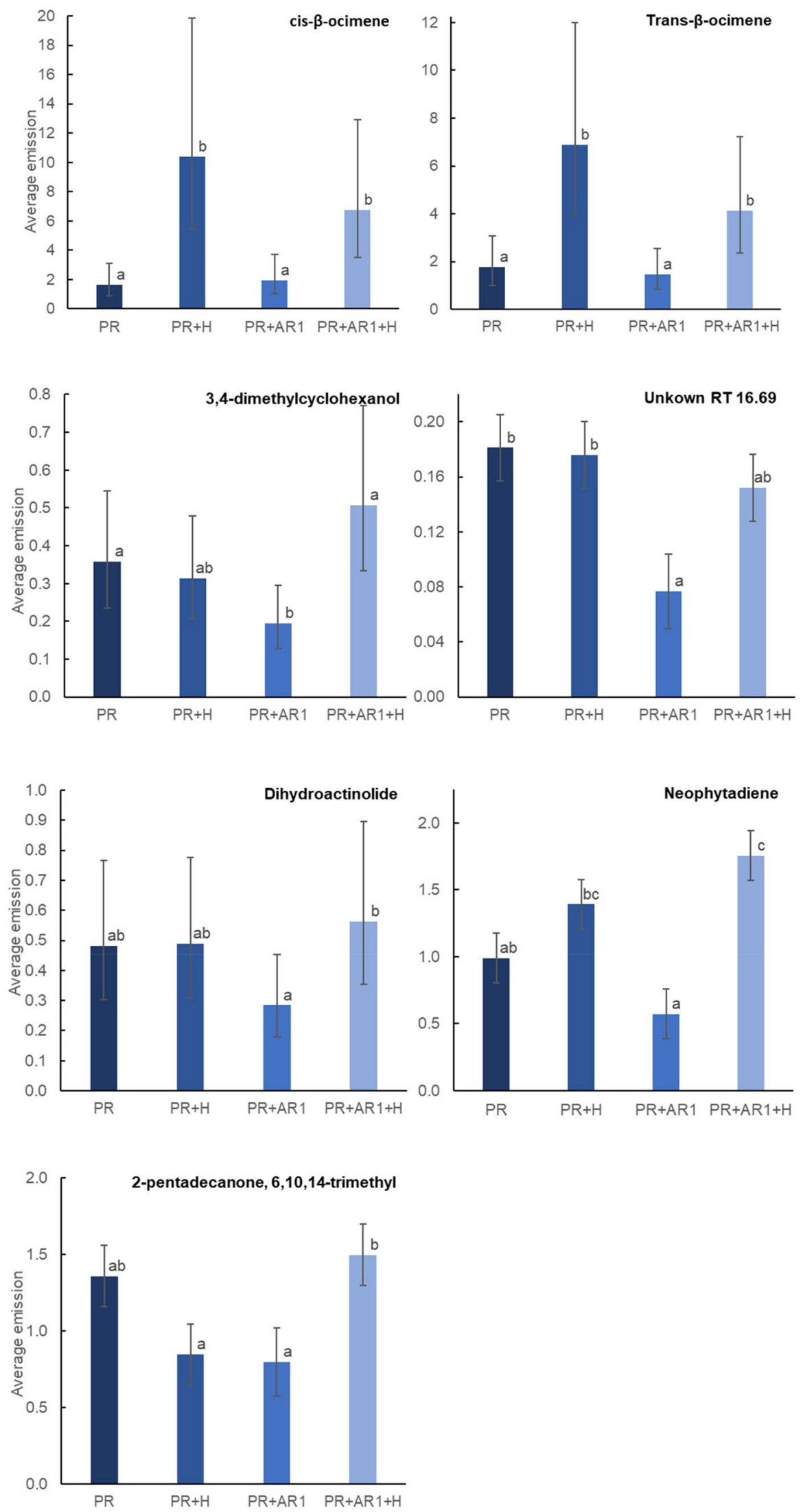


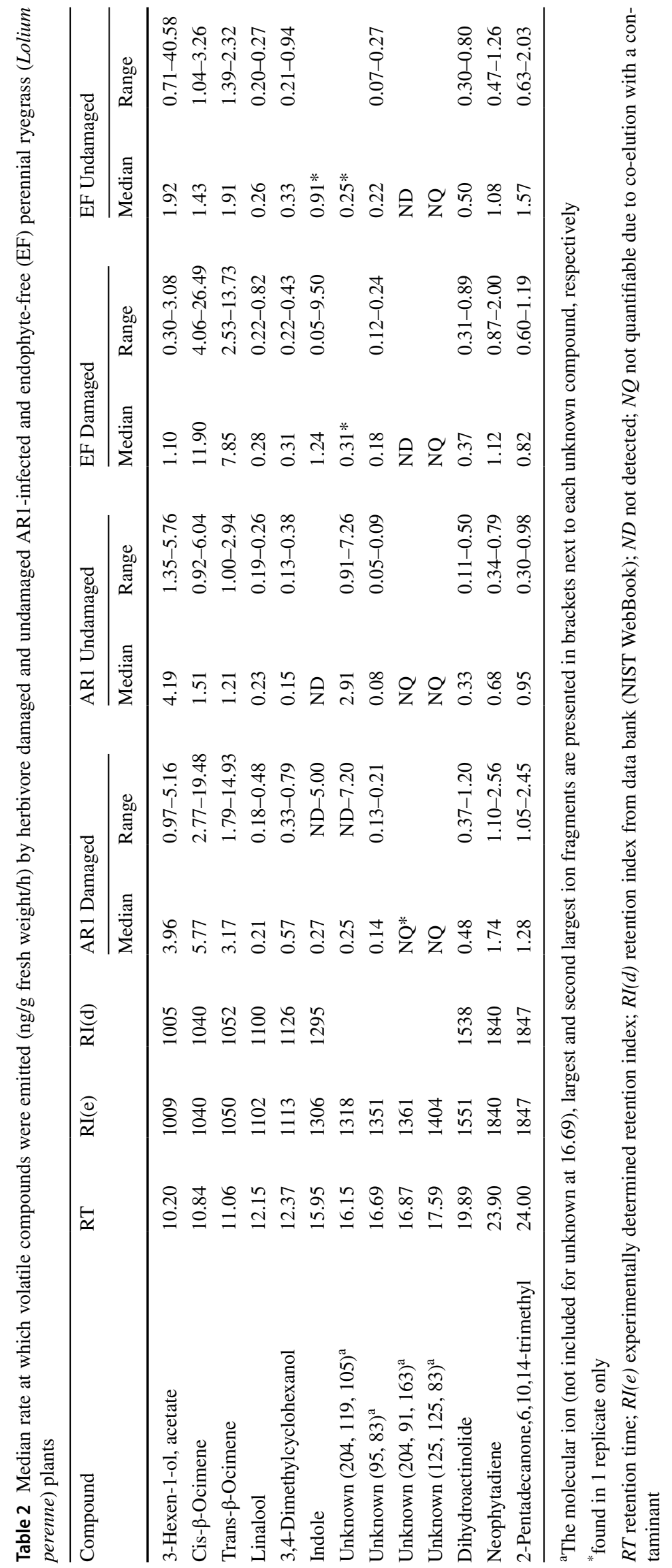




\section{Herbivory}

Significant differences were also found between damaged and undamaged plants. Average emission rates from AR1infected plants were significantly $(P<0.05)$ higher amongst damaged versus undamaged plants for six compounds; cis- $\beta$ ocimene, trans- $\beta$-ocimene, neophytadiene, 3,4-dimethylcyclohexanol, dihydroactinolide and 2-pentadecanone,6,10,14trimethyl (Fig. 4). Fewer significant differences were found between damaged and undamaged endophyte-free plants with the emission of only cis- $\beta$-ocimene and trans- $\beta$ ocimene being significantly $(P<0.05)$ higher in damaged plants (Fig. 4). One qualitative difference was found with the compound indole being emitted by both AR1-infected and endophyte-free damaged plants, but not by equivalent undamaged plants with the exception of one replicate of an endophyte-free undamaged plant.

\section{Endophyte and herbivory}

When investigating the combined effects of endophyte and herbivory (comparing AR1 and endophyte-free damaged plants) the median emission rates of cis- $\beta$-ocimene, trans$\beta$-ocimene and indole were lower in damaged AR1-infected plants, but differences were not significant $(P>0.05)$. In contrast, the emission rates of 3-hexen-1-ol acetate and 2-pentadecanone,6,10,14-tryimethyl were higher in damaged AR1-infected plants and this difference was significant $(P<0.05)$ for the latter compound.

A false discovery rate correction was applied; cis$\beta$-ocimene $(P(\mathrm{FDR})=0.00885)$, trans- $\beta$-ocimene $(P$ $(\mathrm{FDR})=0.00885)$, neophytadiene $(P(\mathrm{FDR})=0.00885)$, 3,4-dimethylcyclohexanol $(P(\mathrm{FDR})=0.0732)$, unknown compound found at retention time $16.69(P(\mathrm{FDR})=0.106)$, 2-pentadecanone, 6, 10, 14-trimethyl $(P(\mathrm{FDR})=0.119)$, dihydroactinolide $(P(\mathrm{FDR})=0.272)$, 3-hexen-1-ol, acetate $(P($ FDR $)=0.317)$, linalool $(P($ FDR $)=0.449)$, indole $(P$ $(\mathrm{FDR})=0.449)$, unknown compound found at retention time $16.14(P(\mathrm{FDR})=0.449)$.

\section{Discussion}

The results from this study provide the first evidence that ASW adults utilize olfaction to orient towards the volatile blend released by perennial ryegrass, an agricultural grass species that is widely cultivated in temperate countries. This is in contrast to the study of Pilkington (1987) who assessed ASW responses to endophyte-free and endophyte-infected perennial ryegrass (cultivar 'Nui') and identified no chemotactic behaviour. We assume that no responses were observed because a four-arm-olfactometer with dynamic airflow (Vet et al. 1983) was used and the maximum observation time was $1 \mathrm{~h}$ per weevil. It is possible that these weevils did not show any chemotactic orientation because of a constant stream of air or maybe the observation time was too short. Hints that ASW could respond to plant volatiles in a stillair olfactometer when given sufficient time, as used in this study, are to be found in unpublished results that show that diapausing ASW respond positively to Italian ryegrass ( $L$. multiflorum) volatiles (J. Vereijssen, personal communication). Host searching has also been assessed in the congeneric species, L. maculicollis, a pest of turfgrass in the United States of America. Like ASW, females of this species were shown to move towards the volatile blend released by their host plant, Poa апnиa (McGraw et al. 2011). Poa annua is a volunteer grass in pastures in New Zealand and a known host of ASW along with Italian ryegrass, tall fescue (Festuca arundinacea), meadow fescue (Festuca pratensis), maize (Zea mays), barley (Hordeum vulgare) and wheat (Triticum spp.) (Barker et al. 1983; Jensen et al. 2009; Kain and Barker 1966; Pottinger 1961). It would be of interest for future host selection studies to identify whether the volatile blends emitted by each of these alternative hosts are also attractive to ASW adults and to determine whether ASW show any preference between species.

In our opinion, the greater attraction of weevils to plants damaged by conspecific insects, observed in this study, is likely to be advantageous for host-searching weevils in New Zealand's pastoral ecosystems. Endophyte-free plants are damaged more frequently and to a greater extent than plants infected with bioactive endophyte strains that produce peramine (Popay et al. 1999; Popay and Wyatt 1995) which is a strong deterrent to adult weevils (Rowan et al. 1990). Therefore, movement towards HIPVs would assist the weevils in locating favourable endophyte-free hosts. This would be an advantage in New Zealand's intensive pasture systems where infection rates of ryegrass with peramine-producing strains are often greater than 70\% (Hume and Barker 2005; Hume et al. 2013). Further, HIPVs are known to also act as indirect plant defence mechanisms by attracting predators and parasitoids of the attacking phytophagous insect (Fuchs and Krauss 2019). The parasitic wasp, M. hyperodae, was introduced to New Zealand to control ASW (Goldson et al. 1990) and, although responses to HIPVs have never been assessed, it is conceivable that this wasp could also utilise these chemical cues when searching for weevils to parasitize. The primitive habitat and 'centre-of-origin' of ASW are thought to be in the 'Mallines' of Argentina (Lloyd 1966). Endophytes have been found in some native grasses in Argentina (Iannone et al. 2012, 2011), but researchers are yet to identify whether endophyte-infected grasses are found in the 'Mallines'. Population sizes in the 'Mallines' are believed to be small (Lloyd 1966) and in these habitats ASW may have relied on HIPVs to locate mates, as plant volatiles can be detected over greater distances than insect 
pheromones (Dickens et al. 1993; Ruther et al. 2000), as well as aiding in location of dispersed hosts. Locating mates in New Zealand's pastoral ecosystems is unlikely to be as challenging for this weevil as populations as high as 436 per square meter have been reported (Goldson et al. 1998a, 1999).

Argentine stem weevils have been shown to respond to conspecific herbivory in a previous, unpublished study (J. Dohmen-Vereijssen, personal communication), where significantly more over-wintering (reproductive diapause) ASW (mixed sex) oriented towards damaged Italian ryegrass plants (endophyte-free, cultivar 'Tama', tetraploid grass) over equivalent undamaged plants. Positive responses towards damaged host plants have also been observed in other weevil species such as the pepper weevil (Anthonomus eugenii) (Addesso et al. 2011) and the vine weevil (Otiorhynchus sulcatus, Coleoptera: Curculionidae), but in the case of the latter, this interaction was dependent on the host plant; damaged yew (Taxus baccata) and spindle trees (Euonymus fortune) were attractive whereas Rhododendron and strawberry (Fragaria $x$ ananassa) were not (Van Tol et al. 2002). Volatile analyses performed in the present study found that damaged perennial ryegrass plants released higher concentrations of several compounds including cis- and trans- $\beta$-ocimene and indole. Indole is a known HIPV and is induced by damage in several other plant species including maize (Zea mays) (Degen et al. 2012; Erb et al. 2015), lima bean (Phaseolus lunatus) and cotton (Gossypium hirsutum) (McCall et al. 1994). Indole was emitted by one of the five replicates of undamaged plants assessed in this study. It may be that indole is also produced constitutively as variability between individual plants can be high or this may have been a result of accidental damage from another pest, such as an aphid or mealybug, or mechanical damage.

In this study, we were unable to demonstrate that plant volatiles were involved in endophyte-mediated defence of perennial ryegrass. Results from our feeding scar assessment, however, support conclusions from previous studies that ASW adults are deterred from feeding on perennial ryegrass infected with the AR1 or WT endophytes (Barker et al. 1984b; Popay et al. 1999; Popay and Thom 2009). It is likely that perception of the endophyte by Argentine stem weevil is mediated by either contact (gustatory) chemoreception or a post-ingestional malaise. Exploiting volatile emissions to avoid endophyte-infected plants can be advantageous for host-searching insects; energy may be conserved and the insect may avoid ingesting harmful metabolites. However, the usefulness of exploiting such cues in New Zealand's intensive pastoral ecosystems, where endophyteinfected and endophyte-free plants are grown in close proximity is unknown. ASW did not co-evolve with Epichloë festucae var. lolii and perhaps, selection pressure on ASW has not sufficed for them to evolve an ability to identify and avoid the volatile blend emitted by endophyte-infected hosts in New Zealand's pastoral ecosystems. ASW have been in New Zealand for $>100$ years but it is only in the last 40 years that endophytes have been commercialised and farming has intensified to the point that lowland pastures are regularly renewed. The primary defensive mechanism of these endophytes appears to be bioactive alkaloids which, evidence suggests, have antifeedant rather than strictly toxic effects on adults (Popay et al. 1990). Antifeedants exert less selection pressure than toxins as the insect can find alternative hosts and survives to reproduce whereas ingestion of toxic plant material will result in death. Furthermore, in planta alkaloid concentrations are known to fluctuate as they can be strongly influenced by many abiotic and biotic factors (Hennessy et al. 2016; Thom et al. 2013). As a result, it is possible for endophyte-infected plants to contain alkaloid concentrations which are below bioactive thresholds for all or part of the year (Ball et al. 1991; Fletcher et al. 2006; Hennessy et al. 2016; Popay et al. 2003a). The first generation of ASW emerge in the spring when alkaloid concentrations are lower. In addition, farmland in New Zealand contains low species diversity (Goldson et al. 2020) which means that thousands of perennial ryegrass plants are grown in close proximity, allowing weevils to move between plants without expending too much energy.

Nine of the thirteen compounds emitted by perennial ryegrass were tentatively identified in the present study and we showed that endophyte influenced the various quantities and identities of the volatile compounds emitted. These may present odour cues for insects to exploit. Perennial ryegrass volatiles have been analysed in two other studies (Pańka et al. 2013; Qawasmeh et al. 2015). Pańka et al. (2013) collected and identified the volatiles released by three genotypes of perennial ryegrass collected from Poland and Austria. Endophyte-free plants and plants infected with an unidentified strain of E. festucae var. lolii were sampled and eight volatiles were identified. In line with our findings, linalool, indole and cis- $\beta$-ocimene (also known as (Z)-ocimene) were identified. Conversely, in assessing the same cultivar ('Grasslands Samson') and endophyte strain (AR1), the present study did not identify any of the 18 volatile compounds reported by Qawasmeh et al. (2015) in their analysis of endophyte-free and endophyte-infected (AR1, WT and AR37) perennial ryegrass. Furthermore, there were also no similarities between the volatile profiles reported by Pańka et al. (2013) and Qawasmeh et al. (2015). Some of this variation may be explained by differences in volatile collection methods as well as host plant genotype, age and environmental conditions (Yue et al. 2001). There is no doubt that further investigation of the volatile profile emitted by perennial ryegrass is required.

More specifically, both qualitative and quantitative differences were identified between the volatile blends emitted 
by the endophyte-infected and endophyte-free ryegrass hosts in the present study. Yue et al. (2001) also reported quantitative and qualitative differences in the volatile blend emitted by endophyte-infected (E. coenophiala) and endophyte-free tall fescue. However, Qawasmeh et al. (2015) and Pańka et al. (2013) reported only quantitative differences. In addition, Li et al. (2014) investigated emissions of volatiles from meadow fescue (Festuca pratensis) and reported that emissions from plants infected with $E$. uncinata were significantly lower than endophyte-free plants. This narrative is obviously complex and the mechanisms underlying endophyte-mediated changes in volatile emissions have yet to be understood (Qawasmeh et al. 2015; Rostás et al. 2015).

To conclude, ASW adults were able to utilise olfaction to orient towards the volatiles released by perennial ryegrass and weevils displayed a preference for plants already damaged by conspecific weevils. However, we found no evidence that ASW use olfaction to distinguish between endophyteinfected (AR1 and WT strains) and endophyte-free plants. We therefore hypothesize that ASW must rely on cues gathered after they have contacted the plant to detect and avoid those that contain bioactive endophyte strains. These results contrast with two previous studies which determined that two beetle species were able to exploit volatile blends to avoid endophyte-infected grasses. Research investigating the mechanisms involved in perception of endophyte by hostsearching insects are sparse and further research is required to fully understand these complex interactions as insights can identify opportunities for improving endophyte-mediated control of pests of agricultural grasses.

Supplementary Information The online version contains supplementary material available at https://doi.org/10.1007/s10340-021-01375-2.

Acknowledgment We would like to acknowledge the financial support provided by AgResearch, Bio Protection Research Centre and the T. R. Ellett Agricultural Trust. We thank Jason Breitmeyer for providing technical support with GCMS, Jan Sprosen for developing endophyte blot sheets and AgResearch scientists Stephen Goldson, Scott Hardwick and David Hume for reviewing this manuscript.

Author contributions $\mathrm{LH}$ carried out this research as a part of her $\mathrm{PhD}$ and wrote the manuscript. AP was the main supervisor of all experimental work involving insects. MR oversaw all the chemical analyses and had input on insect experiments. TG was an associate supervisor and provided insect expertise. SF was an associate co-supervisor and provided chemistry expertise. VC provided statistical expertise.

Funding This work was supported by an AgResearch PhD stipend, operating costs provided by T. R. Ellett trust and a Bio Protection Research Centre writing scholarship.

\section{Declarations}

Conflict of interests AP is a patent holder for AR1 and AP and SF receive research funding from the IP owner Grasslanz Technology Ltd, and licensee, PGG Wrightson Seeds. All the other authors declare that the research was conducted in the absence of any commercial or financial relationships that could be construed as a potential conflict of interest.

Open Access This article is licensed under a Creative Commons Attribution 4.0 International License, which permits use, sharing, adaptation, distribution and reproduction in any medium or format, as long as you give appropriate credit to the original author(s) and the source, provide a link to the Creative Commons licence, and indicate if changes were made. The images or other third party material in this article are included in the article's Creative Commons licence, unless indicated otherwise in a credit line to the material. If material is not included in the article's Creative Commons licence and your intended use is not permitted by statutory regulation or exceeds the permitted use, you will need to obtain permission directly from the copyright holder. To view a copy of this licence, visit http://creativecommons.org/licenses/by/4.0/.

\section{References}

Addesso KM, McAuslane HJ, Alborn HT (2011) Attraction of pepper weevil to volatiles from damaged pepper plants. Entomol Exp Appl 138:1-11

Ball OJ-P, Prestidge RA, Sprosen JM, Lauren DR (1991) Seasonal levels of peramine and lolitrem B in Acremonium lolii-infected perennial ryegrass. Proceedings of the 44th New Zealand Weed Pest Control Conference pp. 176-180

Barker GM, Pottinger RP (1986) Diel activity of the adult Argentine stem weevil. N Z J Zool 13:199-202

Barker GM, Pottinger RP, Addison PJ (1983) Effect of tall fescue and ryegrass endophytes on Argentine stem weevil. Proc N Z Weed Pest Control Conf 36:216-219

Barker GM, Pottinger RP, Addison PJ (1984a) Effect of Lolium endophyte fungus infections on survival of larval Argentine stem weevil. N Z J Agric Res 27:279-281

Barker GM, Pottinger RP, Addison PJ, Prestidge RA (1984b) Effect of Lolium endophyte fungus infections on behaviour of adult Argentine stem weevil. N Z J Agric Res 27:271-277

Benjamini Y, Hochberg Y (1995) Controlling the false discovery rate: a practical and powerful approach to multiple testing. J Roy Stat Soc: Ser B (Methodol) 57:289-300

Bernasconi ML, Turlings TCJ, Ambrosetti L, Bassetti P, Dorn S (1998) Herbivore-induced emissions of maize volatiles repel the corn leaf aphid, Rhopalosiphum maidis. Entomol Exp Appl 87:133-142

Caradus J, Lovatt S, Belgrave B (2013a) Adoption of forage technologies. Proc N Z Grassl Ass 75:39-44

Caradus J, Lovatt S, Belgrave B (2013) Adoption of forage technologies by New Zealand farmers-case studies. Proc Int Grassl Congr 22:1843-1845

Clay K (1988) Fungal endophytes of grasses: a defensive mutualism between plants and fungi. Ecology 69:10-16. https://doi.org/10. 2307/1943155

Degen T, Bakalovic N, Bergvinson D, Turlings TCJ (2012) Differential performance and parasitism of caterpillars on maize inbred lines with distinctly different herbivore-induced volatile emissions. PLOS ONE 7:e47589

Delphia CM, Mescher MC, De Moraes CM (2007) Induction of plant volatiles by herbivores with different feeding habits and the effects of induced defenses on host-plant selection by thrips. J Chem Ecol 33:997-1012

Dicke M, Baldwin IT (2010) The evolutionary context for herbivoreinduced plant volatiles: beyond the 'cry for help.' Trends Plant Sci 15:167-175 
Dickens JC, Smith JW, Light DM (1993) Green leaf volatiles enhance sex attractant pheromone of the tobacco budworm, Heliothis virescens (Lepidoptera: Noctuidae). Chemoecology 4:175-177

Easton HS, Lane GA, Tapper BA, Keogh RG, Blackwell M, Anderson M, Fletcher LR (1996) Ryegrass endophyte-related heat stress in cattle. Proc N Z Grassl Ass 57:37-41

Erb M, Veyrat N, Robert CAM, Xu H, Frey M, Ton J, Turlings TCJ (2015) Indole is an essential herbivore-induced volatile priming signal in maize. Nat Commun 6:6273

Esteban FJ, Carina FP, Marina O (2021) Z-3-Hexenylacetate emissions induced by the endophyte Epichloë occultans at different levels of defoliation during the host plant's life cycle. Fungal Ecol 49:101015

Ferguson CM et al (2018) Quantifying the economic cost of invertebrate pests to New Zealand's pastoral industry. N Z J Agric Res 62:255-315

Finch SC et al (2020) Identification and structure elucidation of epoxyjanthitrems from Lolium perenne infected with the endophytic fungus Epichloë festucae var Lolii and determination of the tremorgenic and anti-insect activity of epoxyjanthitrem I. Toxins 12:526

Finch SC, Wilkins AL, Popay AJ, Babu JV, Tapper BA, Lane GA (2010) The isolation and bioactivity of epoxy-janthitrems from AR37 endophyte-infected perennial ryegrass. Paper presented at the Proceedings of the 7th International Symposium on Fungal Endophytes of Grasses, Lexington, Kentucky, USA

Fletcher LR, Easton S, Popay A, Tapper B, Hume D (2006) Plant and endophyte genotype affects peramine concentrations in ryegrass/endophyte associations. Adv Plant Breed Grassl Res Pract Ser 12:93-96

Fuchs B, Krauss J (2019) Can Epichloë endophytes enhance direct and indirect plant defence? Fungal Ecol 38:98-103

Gallagher RT, Hawkes AD, Steyn PS, Vleggaar R (1984) Tremorgenic neurotoxins from perennial ryegrass causing ryegrass staggers disorder of livestock: structure elucidation of lolitrem B. J Chem Soc, Chem Commun 9:614-616

Gallagher RT, White EP, Mortimer PH (1981) Ryegrass staggers: isolation of potent neurotoxins lolitrem A and lolitrem B from staggers-producing pastures. N Z Vet J 29:189-190

Goldson SL (1981) Reproductive diapause in the Argentine stem weevil, Listronotus bonariensis, (Kuschel)(Coleoptera: Curculionidae), in New Zealand. Bull Entomol Res 71:275-287

Goldson SL, Barker GM, Barratt BIP, Barlow ND (1994) Progress in the biological control of Argentine stem weevil and comment on its potential. Proc N Z Grassl Ass 56:39-42

Goldson SL, Barker GM, Chapman HM, Popay AJ, Stewart AV, Caradus JR, Barratt BIP (2020) Severe insect pest impacts on New Zealand pasture the plight of an ecological outlier. J Insect Sci 20:17

Goldson SL, Emberson RM (1981) Reproductive morphology of the Argentine stem weevil, Hyperodes bonariensis (Coleoptera: Curculionidae). N Z J Zool 8:67-77

Goldson SL, McNeill MR, Stufkens MW, Proffitt JR, Pottinger RP, Farrell JA (1990) Importation and quarantine of Microctonus hyperodae, a South American parasitoid of Argentine stem weevil. Proc N Z Weed Pest Control Conf 43:334-338

Goldson SL, Proffitt JR, Baird DB (1998) The bionomics of Listronotus bonariensis (Coleoptera: Curculionidae) in Canterbury, New Zealand. Bull Entomol Res 88:415-423

Goldson SL, Proffitt JR, Baird DB (1998) Establishment and phenology of the parasitoid Microctonus hyperodae (Hymenoptera: Braconidae) in New Zealand. Environ Entomol 27:1386-1392

Goldson SL, Proffitt JR, Baird DB (1999) Listronotus bonariensis (Coleoptera: Curculionidae) flight in Canterbury, New Zealand. Bull Entomol Res 89:423-431
Hardy RJ et al. (1979) Insect pest survey. Tasmanian Department of Agriculture Report 11

Hennessy LM, Popay AJ, Finch SC, Clearwater MJ, Cave VM (2016) Temperature and plant genotype alter alkaloid concentrations in ryegrass infected with an Epichlö̈ endophyte and this affects an insect herbivore. Front Plant Sci 7:1097

Hume DE, Barker DJ (2005) Growth and management of endophytic grasses in pastoral agriculture. In: Roberts GA, West CP, Spiers DE (eds) Neotyphodium in cool-season grasses. Blackwell Publishing, USA, pp 201-226

Hume DE, Card SD, Rolston MP Effects of storage conditions on endophyte and seed viability in pasture grasses. In: Michalk DL, Millar GD, Badgery WB, Broadfoot KM (eds) Proceedings of the 22nd International Grassland Congress, Sydney, Australia, 2013. pp 405-408

Iannone LJ, Novas MV, Young CA, De Battista JP, Schardl CL (2012) Endophytes of native grasses from South America: biodiversity and ecology. Fungal Ecol 5:357-363

Iannone LJ, White JF, Giussani LM, Cabral D, Novas MV (2011) Diversity and distribution of Neotyphodium-infected grasses in Argentina. Mycol Prog 10:9-19

Jensen JG, Popay AJ (2007) Reductions in root aphid populations by non-toxic endophyte strains in tall fescue. Proc 6th Int Sympo of Fungal Endophyte Grasses Grassl Res Pract Ser 13:341-344

Jensen JG, Popay AJ, Tapper BA (2009) Argentine stem weevil adults are affected by meadow fescue endophyte and its loline alkaloids. N Z Plant Prot 62:12-18

Johnson LJ, Caradus JR (2019) The science required to deliver Epichloë endophytes to commerce. Cambridge University Press, Cambridge, Endophytes for a Growing World

Johnson LJ et al (2013) The exploitation of epichloae endophytes for agricultural benefit. Fungal Divers 60:171-188. https://doi.org/ 10.1007/s13225-013-0239-4

Kain WM, Barker MA (1966) Argentine stem weevil: a pest of maize. Proc N Z Weed Pest Control Conf 19:180-185

Latch GCM, Christensen MJ (1985) Artificial infection of grasses with endophytes. Ann Appl Biol 107:17-24

Li T, Blande JD, Gundel PE, Helander M, Saikkonen K (2014) Epichloë endophytes alter inducible indirect defences in host grasses. PLoS ONE 9:e101331

Lloyd DC (1966) Natural enemies of the stem weevil Hyperodes bonariensis Kuschel in South America. Commonwealth Institute of Biological Control, Mimeographed Report

McCall PJ, Turlings TCJ, Loughrin J, Proveaux AT, Tumlinson JH (1994) Herbivore-induced volatile emissions from cotton (Gossypium hirsutum L.) seedlings. J Chem Ecol 20:3039-3050

McGraw BA, Rodriguez-Saona C, Holdcraft R, Szendrei Z, Koppenhöfer AM (2011) Behavioral and electrophysiological responses of Listronotus maculicollis (Coleoptera: Curculionidae) to volatiles from intact and mechanically damaged annual bluegrass. Environ Entomol 40:412-419

Pańka D, Piesik D, Jeske M, Baturo-Cieśniewska A (2013) Production of phenolics and the emission of volatile organic compounds by perennial ryegrass (Lolium perenne L.)/Neotyphodium lolii association as a response to infection by Fusarium poae. J Plant Physiol 170:1010-1019

Patchett B, Gooneratne R, Chapman B, Fletcher L (2011) Effects of loline-producing endophyte-infected meadow fescue ecotypes on New Zealand grass grub (Costelytra zealandica). N Z J Agric Res 54:303-313

Pilkington S (1987) The behavioural biology of Argentine stem weevil in relation to host-plant characters. Massey University, Masters

Popay AJ, Baltus JG (2001) Black beetle damage to perennial ryegrass infected with AR1 endophyte. Proc N Z Grassl Ass 63:267-272 
Popay AJ, Cox NR (2016) Aploneura lentisci (Homoptera: Aphididae) and its interactions with fungal endophytes in perennial ryegrass (Lolium perenne). Front Plant Sci 7

Popay AJ et al (1999) Field performance of perennial ryegrass (Lolium perenne) infected with toxin-free fungal endophytes (Neotyphodium spp.). Ryegrass Endophyte essent N Z Symbiosis Grassl Res Pract Ser 7:113-122

Popay AJ, Hume DE, Davis KL, Tapper BA (2003) Interactions between endophyte (Neotyphodium spp.) and ploidy in hybrid and perennial ryegrass cultivars and their effects on Argentine stem weevil (Listronotus bonariensis). N Z J Agric Res 46:311-319. https://doi.org/10.1080/00288233.2003.9513559

Popay AJ, Prestidge RA, Rowan DD, Dymock JJ (1990) The role of Acremonium lolii mycotoxins in insect resistance of perennial ryegrass (Lolium perenne). In: Quisenberry SS, Joost RE (eds) Proceedings of the International Symposium on Acremonium/ Grass Interactions. Louisiana Agricultural Experimental Station, New Orleans, pp 44-48

Popay AJ, Thom ER (2009) Endophyte effects on major insect pests in Waikato dairy pasture. Proc N Z Grassl Ass 71:121-126

Popay AJ, Townsend RJ, Fletcher LR (2003) The effect of endophyte (Neotyphodium uncinatum) in meadow fescue on grass grub larvae. N Z Plant Prot 56:123-128

Popay AJ, Wyatt RT (1995) Resistance to Argentine stem weevil in perennial ryegrass infected with endophytes producing different alkaloids. Proc N Z Plant Prot Conf 48:229-236

Pottinger RP (1961) A study on the biology and economic importance of the Argentine stem weevil, Hyperodes bonariensis kuschel, in New Zealand. Canterbury Agricultural College, University of New Zealand, Masters

Prestidge RA, Barker GM, Pottinger RP (1991) The economic cost of Argentine stem weevil in pastures in New Zealand. Proc N Z Weed Pest Control Conf 44:165-170

Prestidge RA, Gallagher RT (1985) Lolitrem B - a stem weevil toxin isolated from Acremonium-infected ryegrass. Proc N Z Weed Pest Control Conf 38:38-40

Prestidge RA, Pottinger RP, Barker GM (1982) An association of Lolium endophyte with ryegrass resistance to Argentine stem weevil. Proc N Z Weed Pest Control Conf 35:119-122

Qawasmeh A, Raman A, Wheatley W (2015) Volatiles in perennial ryegrass infected with strains of endophytic fungus: impact on African black beetle host selection. J Appl Entomol 139:94-104

Rolston MP, Hare MD, Moore KK, Christensen MJ (1986) Viability of Lolium endophyte fungus in seed stored at different moisture contents and temperatures. N Z J Exp Agric 14:297-300

Rostás M, Cripps MG, Silcock P (2015) Aboveground endophyte affects root volatile emission and host plant selection of a belowground insect. Oecologia 177:487-497

Rowan DD, Dymock JJ, Brimble MA (1990) Effect of fungal metabolite peramine and analogs on feeding and development of
Argentine stem weevil (Listronotus bonariensis). J Chem Ecol 16:1683-1695

Rowan DD, Gaynor DL (1986) Isolation of feeding deterrents against Argentine stem weevil from ryegrass infected with the endophyte Acremonium loliae. J Chem Ecol 12:647-658

Rowan DD, Hunt MB, Gaynor DL (1986) Peramine, a novel insect feeding deterrent from ryegrass infected with the endophyte Acremonium loliae. J Chem Soc, Chem Commun 12:935-936

Rowan DD, Shaw GJ (1987) Detection of ergopeptine alkaloids in endophyte-infected perennial ryegrass by tandem mass spectrometry. N Z Vet J 35:197-198

Ruther J, Reinecke A, Thiemann K, Tolasch T, Francke W, Hilker M (2000) Mate finding in the forest cockchafer, Melolontha hippocastani, mediated by volatiles from plants and females. Physiol Entomol 25:172-179

Simpson WR, Schmid J, Singh J, Faville MJ, Johnson RD (2012) A morphological change in the fungal symbiont Neotyphodium lolii induces dwarfing in its host plant Lolium perenne. Fungal Biol 116:234-240

Szendrei Z, Rodriguez-Saona C (2010) A meta-analysis of insect pest behavioral manipulation with plant volatiles. Entomol Exp Appl 134:201-210

Tapper BA, Latch GCM (1999) Selection against toxin production in endophyte-infected perennial ryegrass. Ryegrass Endophyte: essent N Z Symbiosis Grassl Res Pract Ser 7:107-111

Thom ER, Popay AJ, Waugh CD, Minneé EMK (2013) Impact of novel endophytes in perennial ryegrass on herbage production and insect pests from pastures under dairy cow grazing in Northern New Zealand. Grass Forage Sci 69:191-204

Turlings TCJ, Tumlinson JH, Lewis WJ (1990) Exploitation of herbivore-induced plant odors by host-seeking parasitic wasps. Science 250:1251-1253

Van Tol RWHM, Visser JH, Sabelis MW (2002) Olfactory responses of the vine weevil, Otiorhynchus sulcatus, to tree odours. Physiol Entomol 27:213-222

Vet LEM, van Lenteren JC, Heymans M, Meelis E (1983) An airflow olfactometer for measuring olfactory responses of hymenopterous parasitoids and other small insects. Physiol Entomol 8:97-106

Williams CL, Goldson SL, Baird DB, Bullock DW (1994) Geographical origin of an introduced insect pest, Listronotus bonariensis (Kuschel), determined by RAPD analysis. Heredity 72:412

Yue Q, Wang C, Gianfagna TJ, Meyer WA (2001) Volatile compounds of endophyte-free and infected tall fescue (Festuca arundinacea Schreb.). Phytochemistry 58:935-941

Publisher's Note Springer Nature remains neutral with regard to jurisdictional claims in published maps and institutional affiliations. 